\title{
Baboons as potential reservoirs of zoonotic gastrointestinal parasite infections at Yankari National Park, Nigeria
}

\author{
Mafuyai HB, *Barshep Y, Audu BS, Kumbak D, Ojobe TO \\ Department of Zoology, University of Jos, PMB 2040, Plateau State, Nigeria
}

\begin{abstract}
Background: Zoonoses pose a risk to public health.

Objective: To carry out the investigation of the prevalence of gastrointestinal parasites of baboons, Papio anubis, frequenting the Wikki base Camp in Yankari National Park, Nigeria

Method: Formol-ether concentration technique was used to isolate parasite eggs and cysts from faecal samples.

Results: Parasites recovered were Ascaris lumbricoides, Ancylostoma duodenale, Strongyloides stercoralis, Fasciola sp, Schistosoma mansoni, Hymenolepis nana, and Trichostrongylus sp, and cysts of protozoan parasites Entomoeba histolytica, E. coli, and Iodamoeba butschii.

Conclusion: Most of the parasites identified are known to have high pathologic involvement in humans, implicating the baboons as potential source and reservoirs for human zoonotic parasitic infections although further molecular work would be necessary to ascertain if these gastrointestinal parasites are the same strains that infect humans
\end{abstract}

Keywords: Papio anubis, gastrointestinal parasites, zoonoses, Yankari

African Health Sciences 2013; 13(2):252 - 254 http:/ / dx.doi.org/10.4314/ahs.v13i2.7

\section{Introduction}

Zoonoses, infectious diseases transmitted from animals to humans, pose a risk to public health. An estimated $71 \%$ of emerging human pathogens of zoonotic importance have wildlife origins ${ }^{1}$. Some of the factors which may account for this include alteration of the environment, increasing human populations causing an increased level of contact between humans and infected animals, increasing movements of people, and an increased trade in animals and animal products ${ }^{1}$.

The ability of infectious disease agents to cross the species barrier has long been recognised $^{3}$.The role of wildlife in transmitting infections to humans ${ }^{1,2}$, and in maintaining infection through spillover and spillback mechanisms has been explored in many organisms ${ }^{1}$ but more so in nonhuman primates ${ }^{2,3}$. Non-human primates often carry gastrointestinal parasites that have been found to be shared between humans and primates ${ }^{3,4,5}$. These parasites are found in both free-ranging naturally occurring populations as well as populations found

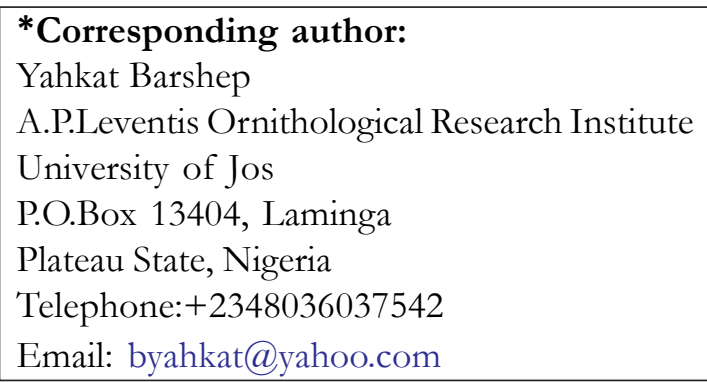

near human-inhabitated areas ${ }^{6,7}$. To recognize and combat zoonotic diseases, we need to identify pathogens, their vertebrate hosts, and consider this in relation to their methods of transmission.

In Yankari National Park in Nigeria, the warm Wikki spring is a favourite tryst for baboons and tourists. Baboons spend considerable periods inside the water swimming and roam freely on the camping grounds in front of the base camp offices, dropping faeces which pollute the soil, predisposing campers to soil borne infections. Aside from putting the health of resident workers in wildlife conservation areas at risk, tourists who frequent and share leisure sites such as the spring waters for bathing/swimming and camping sites with the wildlife are also at risk.

Against this background, the study sought to investigate the prevalence of gastrointestinal parasites in three troops of baboons visiting the Wikki spring base camp, and the possibility of any risk of zoonotic infections.

\section{Methods}

Yankari National Park is located in Bauchi State in the north-eastern part of Nigeria. The park area of about 2,224 square kilometres consists mainly of savannah woodland and riverine forest vegetation along the banks of the river Ghaji (figure. 1). Three natural springs are located within the park of which the Wikki warm spring is the most famous. 


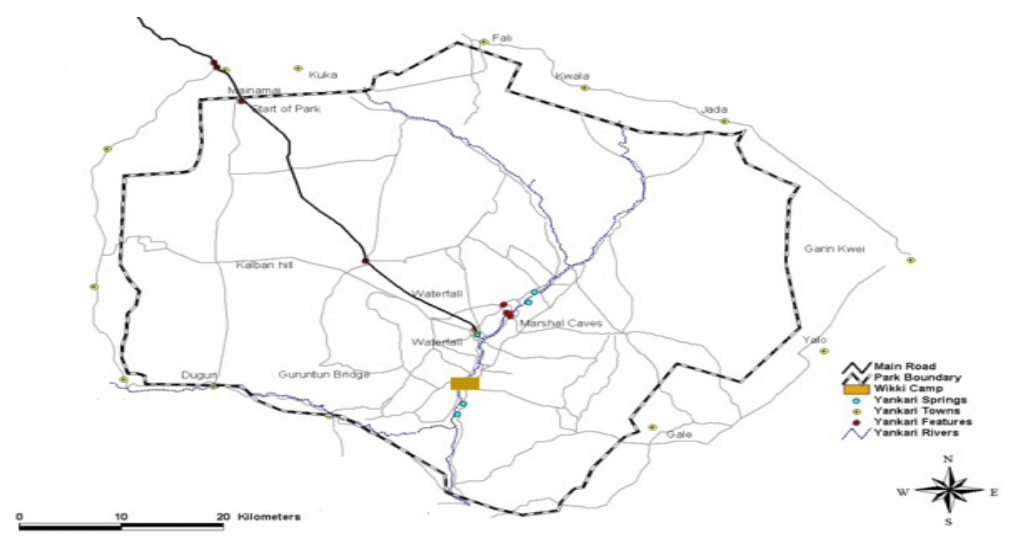

Figure 1: Map of Yankari National Park showing the location of the Wikki Camp

Faecal samples collection and examination

Fresh faecal droppings of baboons were collected between $07 \mathrm{~h} 00$ and $11 \mathrm{~h} 00$ from three separate baboon groups that frequent the Wikki Spring, hostel, and chalet areas. Each group was territorial and defended their area against other groups. The groups frequenting the hostel and chalet area was composed of 15 and 8 individuals, respectively. Because faecal samples were not identified to an individual, it is possible that some samples represent multiple samples from the same individual. Samples were taken from the middle of the faecal dropping and preserved immediately in 10\% formal-saline solution in bijou bottles and stored until required for analysis.

Formol-ether concentration technique ${ }^{8}$ was used to isolate parasite eggs and protozoan cysts from the faecal samples. $1 \mathrm{~g}$ of the faecal specimen mixed with $10 \mathrm{ml}$ of $10 \%$ formal-saline solution was put in a centrifuge tube, thoroughly homogenised, and mixed with $3 \mathrm{mls}$ of ether and vigorously shaken for 30 seconds. The preparation was centrifuged at $3000 \mathrm{rpm}$ for 2 minutes. Faecal debris and fatty deposits at the liquid interphase was loosed with a glass rod and the centrifuge tube rapidly inverted to decant the supernatant. A drop of Lugol's iodine was added to the deposit to aid the identification of protozoan cysts on observation under a light microscope.

\section{Results}

A total of 46 faecal samples were collected and examined. Seven helminth and nematode species were identified and the cysts of Entamoeba histolytica, E. coli and Iodamoeba butschii were also recovered (table 1).

Table 1: Gastrointestinal parasites recovered from 46 faecal samples of Papio anubis at Yankari National Park, Nigeria

\begin{tabular}{lll}
\hline & Parasite species & Number infected \\
\hline Helminth and & Ascaris lumbricoides & 16 \\
nematode species & Ancylostoma duodenale & 3 \\
& Hymenolepis nana & 1 \\
& Fasciola sp. & 2 \\
& Schistosoma mansoni & 2 \\
& Strongyloides stercoralis & 3 \\
& Trichostrongylus sp. & 1 \\
& Total & 28 \\
Protozoa species & Entamoeba histolytica & 46 \\
& Entamoeba coli & 46 \\
& Iodamoeba butschii & 20 \\
\hline
\end{tabular}




\section{Discussion}

In a review of the over 140 zoonotic parasites shared between humans and animals ${ }^{1,2}$, the intestinal parasites recovered in this study are amongst those known to have high pathologic involvement in humans. Heavy infection with $A$. lumbricoides causes diarrhoea, vomiting, and occasionally occlusion of the intestinal tract. The larval stages of these parasites reside in various organs causing trauma and pathology in different viscera ${ }^{9}$. The protozoan parasites E. histolytica and E. coli are considered to be easily transmissible from animals to humans through contaminated food, water and hands ${ }^{10}$. They are known to be the most common causative agents of debilitating diarrhoea in humans.

However, it should be noted that although baboons at YNP showed natural infections with eggs and cysts of helminth, nematode and protozoan parasites that are morphologically similar to those found in humans ${ }^{5,11}$, It would require molecular work to ascertain if these gastrointestinal parasites are of the same strain that infect humans ${ }^{12}$. For instance, Oesophagostamum bifurcum found in non-human primates is a different strain from that which infects humans ${ }^{13}$. Further studies exploring the infection of the workers at YNP with these gastrointestinal parasites would confirm if baboons are indeed reservoir hosts. Also, coprologic studies of gastrointestinal parasites of baboon population far from human habitation could reveal if the parasites found in the baboons at the Wikki Camp are a result of spillover and spillback from humans.

\section{Conclusion}

There is no doubt that anthropogenic changes which increase contact between humans and wildlife will inevitably play a role in the emergence and re-emergence of zoonotic diseases ${ }^{11,14}$. Parasitic disease control programmes should emphasis; limited contact with non-human primates, and vaccination against potentially threatening diseases ${ }^{14}$.

\section{Acknowledgement}

We thank the management and staff of the Yankari National Park for logistic support during the fieldwork, parasitology department of the National Veterinary Research Institute Vom for help with parasite identification, and to an unknown reviewer who provided valuable comments on the manuscript.

\section{References}

1. Brown C. Emerging zoonoses and pathogens of public health significance-an overview. Revue Scientifique et Technique de l Office International des Epizooties. 2004; 23: 435-442.

2. Mahy BWJ, Brown CC. Emerging zoonoses: crossing the species barrier. Revue Scientifique et Technique de l Office International des Epizooties. 2000; 19: 33-40.

3. Ryan SJ, Brashares JS, Walsh C, Milbers K, Kilroy C, Chapman CA. A Survey of Gastrointestinal Parasites of Olive Baboons (Papio anubis) in Human Settlement Areas of Mole National Park, Ghana. Journal of Parasitology. 2012; 98: 885-888.

4. Müller-Graf CDM, Collins DA, Woolhouse MEJ. Intestinal parasite burden in five troops of olive baboons (Papio cynocephalus anubis) in Gombe Stream National Park, Tanzania. Parasitology. 1996; 112: 489497.

5. Muriuki SMK, Murugu RK, Munene E, Karere GM, Chai DC. Some gastro-intestinal parasites of zoonotic (public health) importance commonly observed in old world non-human primates in Kenya. Acta Tropica. 1998; 71: 73-83.

6. Weyher A, Ross C, Semple S. Gastrointestinal parasites in crop raiding and wild foraging Papio anubis in Nigeria. International Journal of Primatology. 2006; 27: 1519-1534.

7. Murray S, Stem C, Boudreau B, Goodall J. Intestinal parasites of baboons (Papio cynocephalus anubis) and chimpanzees (Pan troglodytes) in Gombe National Park. Journal of zoo and wildlife medicine. 2000; 31: 176-178.

8. Chessebrough M. District Laboratory in Tropical Countries, Part 1. Cambridge University press. 1998; Pp: 246-250.

9. Holmes PH. Pathophysiology of parasitic infection. Parasitology. 1987; 94 Suppl:S29-51.

10. Smith JM, Meerovitch E. Primates as a source of Entamoeba histolytica, their zymodeme status and zoonotic potential. Journal of Parasitology. 1985; 71: 751-6.

11. Standley CJ, Mugisha L, Dobson AP, Stothard JR. Zoonotic schistosomiasis in non-human primates: past, present and future activities at the human-wildlife interface in Africa. Journal of Helminthology. 2012; 86: 131-140.

12. de Gruijter JM, Gasser RB, Polderman AM, Asigri V, Dijkshoorn L. High resolution DNA fingerprinting by AFLP to study the genetic variation among Oesophagostomum bifurcum (Nematoda) from human and non-human primates from Ghana. Parasitology. 2005; 130: 229-237.

13. van Lieshout L, de Gruijter JM, Adu-Nsiah M et al. Oesophagostamum bifurcum in non-human primates is not a potential reservoir for human infection in Ghana. Tropical Medicine and International Health. 2005; 10: 1315-1320.

14. Ryan SJ, Walsh PD. Consequences of NonIntervention for Infectious Disease in African Great Apes. PLoS ONE. 2011; 6: e29030. doi:10.1371/ journal.pone.0029030. 